\title{
Cultural Studies and the Limits of Cosmopolitical Theory
}

\section{ADAM GALL}

INDEPENDENT SCHOLAR

Rosi Braidotti, Patrick Hanafin and Bolette Blaagaard (eds)

After Cosmopolitanism

Routledge, New York, 2013

ISBN 9780415627214 RRP US\$48.95

Cosmopolitanism has proved itself a perennial, if not uniformly durable, theoretical concept. Over the last few decades, the term has flowered and died back across multiple fields and subfields in the humanities and social sciences. The title of this collection, After Cosmopolitanism, suggests that current cosmopolitical theory is once again breaking up and plowing under earlier versions of itself. The collection begins by posing the question: 'Is the idea of cosmopolitanism still useful?' (1) The short answer is yes, but only insofar as the 'universalistic, rationalistic, Neo-Kantian transcendental' model of cosmopolitanism is replaced by 'the multi-faceted, affective cosmopolitics of embodied subjectivities grounded in diversity and radical relationality'. (2) Yet, however much debated, the term continues to connote privilege and elitism, as well as a comfortable sense of its thoroughgoing distinction from its supposed antonyms, the patriotic or parochial. Although the editors initially

Cultural Studies Review 2015. @ 2015 Adam Gall. This is an Open Access article distributed under the terms of the Creative Commons Attribution 4.0 Unported (CC BY 4.0) License (https://creativecommons.org/licenses/by/4.0/), allowing third parties to copy and redistribute the material in any medium or format and to remix, transform, and build upon the material for any purpose, even commercially, provided the original work is properly cited and states its license. 
claim that the collection pursues a single argument, they are more correct when they later assert that the chapters are 'multiple variations around the same theme'. (7) Indeed, it is difficult to imagine an anthology framed by this topic that could maintain a high degree of homogeneity.

The chapters can be divided roughly according to their intellectual orientations: there are works of political and legal theory on the one hand, and of social and cultural theory on the other. The representative stoush staged among the legal and political theorists is that between David Held (the collection's token unrepentant universalist, representing liberals, rationalists and Habermasians) and Patrick Hanafin, one of the volume's editors. Held equates cosmopolitanism with 'a rule-based global order' (28) and outlines what he understands as the large-scale, contemporary challenges to such an idea. His discussion has the virtue of acknowledging the existence of Asia, but only to dismiss 'the new Asian powers' (34) as anti-cosmopolitan due to their nationalism and authoritarianism. While this abstracted and simplistic view of 'Asia' will be unacceptable to those familiar with recent work by Partha Chatterjee or Kuan-Hsing Chen, Hanafin is chiefly critical of Held's 'bureaucratic' approach and calls instead for a turn to the embodied and the local. ${ }^{1}$

Hanafin insists that legal and political theory make a shift in scale and emphasis, moving from the what to the who of cosmopolitics. Many in cultural studies will endorse this theoretical gesture to 'the absolute local', (48) while also recognising its familiarity. For several decades feminist cultural studies and human geography have sought to engage the intimately scaled, local perspective using approaches that are methodologically rich in ways that few of the contributions to this volume seem to be. Consider, for example, the tradition in feminist cultural studies of the rigorous use of the anecdotal. For Hanafin, however, as for other theorists, the local represents 'a politics of singularities without identity'. (53) Yet surely identity and identification cross-hatch the local and paying attention to localised forms of world-making will reveal that a politics of 'the absolute local' is far from sufficient in itself?

This point of distinction between cultural studies and cultural theory can be seen more clearly elsewhere. Across the collection various contributions chart the division between so-called normative cosmopolitanism versus what Costas 
Douzinas calls 'the cosmopolitical condition' as 'a set of socio-economic and political arrangements'. (57) However, this binary opposition could be placed under pressure by a third term that includes cultural practices and social identities that can also be described as cosmopolitan. In the Australian context, these practices and identities have often been explored in the realm of consumption, paradigmatically in Ghassan Hage's mid-1990s ethnographically based work on Australian whiteness and multiculturalism. ${ }^{2}$ More recent work on cosmopolitan consumption and policy, as well research into everyday multiculturalism, speaks to a space where the normative and the situational converge. ${ }^{3}$

Another way of identifying the significance of local cosmopolitan practices and identities is to see them in terms of an epistemological problem that has dogged cultural studies since its inception. In his comic book primer to the discipline, Ziauddin Sardar notes that cultural studies attempts 'to overcome the split between tacit (that is, intuitive knowledge based on local cultures) and objective (so-called universal) forms of knowledge'. ${ }^{4}$ Understanding tacit knowledge always presents a methodological challenge although this is not acknowledged in After Cosmopolitanism. It is worth remembering that speaking in the name of the tacit, the local, the affective, is not the same as providing tools for thinking about those things.

Among the chapters which manifest a social and cultural theory orientation to cosmopolitanism are essays by Henrietta Moore, Paul Gilroy, Eugene Holland and Clare Colebrook. Particularly interesting to those who might be unfamiliar with her work is Moore's psychoanalytically informed emphasis on 'fantasy as an aspect of our relations with others'. (102) Moore argues that cosmopolitanism functions as a fantasy image that holds together the mutually contradictory 'distant' and 'intimate' aspects of contemporary life. Although the fantasy of cosmopolitanism 'does not necessarily grant others the freedom to imagine other worlds', (106) Moore nonetheless offers it as a model for 'understanding and theorising ordinary people's experience of, and/or engagement with, diversity and difference'. (100) Moore also suggests that we include the more-than-human in our cosmopolitical thinking, noting the ways in which cultures of cosmopolitanism have now expanded into socio-technical assemblages and also how social movements routinely invoke the political agency of 'earth-beings'. (108) Moore's is one of the few essays in the 
volume that offers ethnography as an appropriate modality for work in this area, though this offer does not include demonstrated application.

Elsewhere, Paul Gilroy offers a diagnosis of the 'melancholic cycle of guilty evasion, filtering, refusal and blockage' (116) that marks contemporary European cosmopolitanism and will continue to do so until it integrates its colonial and imperial inheritance. Gilroy seeks a 'worldly reflexivity', (127) a new sense of community that sits somewhere between the 'cosmopolitan' spirit of capital and that of its insurgent opponents. While Gilroy foregrounds Western Europe, recent work by Greg Noble and others has shown that Gilroy's vocabulary of cosmopolitan conviviality translates beyond the European frame, as indeed does the account of postcolonial melancholia. Gilroy's attention to cultures of cosmopolitanism and the forces that mitigate against them, represents another direct address to the methodological concerns of cultural studies. Unfortunately the methodological payoff remains more alluded to than real: Gilroy listens for some of Europe's 'minor voices', (125) such as the work of the artist Anselm Kiefer, in which he finds 'the cultural dimensions of post-colonial Europe's belated working-through'. (126)

The essays by Moore and Gilroy aside, in much of the volume the location of theory remains implicit, unacknowledged and unexamined. This parallels, without exactly replicating, the blindness to Eurocentrism and to privilege which has been attributed to earlier versions of cosmopolitanism. By and large, the contributors are talking mostly from and about 'Europe' or, at a stretch, 'the North Atlantic' without acknowledging the implicit borders to their inquiry. This is in spite of the frontispiece argument from Rosi Braidotti that 'a new agenda needs to be set, which is no longer that of European or Eurocentric identity, but rather a radical transformation of it'. (17) Braidotti, for her part, equates Eurocentrism with methodological nationalism thereby ignoring the fact that in many places forms of methodological nationalism may be a real, if not unproblematic, way of challenging Eurocentric knowledge production. Despite her own best intentions, Braidotti demonstrates how one can remain doggedly Eurocentric while still avowing 'chaosmopolitan nomadism' and 'the becoming-world of subjectivity itself'. (20) The fault is hardly Braidotti's alone and given that this is a collection that interrogates cosmopolitanism and, for the most part, positions itself against a universalising 
version of it, one might have hoped that the limits of the known world could have been pushed back a little.

Amid these chiefly theoretical discussions, After Cosmopolitanism includes some examples of concrete cultural analysis. Lilie Chouliaraki's critique of posthumanitarian discourse and Sneja Gunew's examination of contemporary literary cosmopolitanisms fit most clearly into this category. While these chapters cite and contribute to the governing debates of the field, each also engages in work that is recognisably textual in its methods. For Chouliaraki, that means close attention paid to the particularities of texts, including materials from the United Nations, nongovernmental organisations and various media. From these document sources, she outlines the limitations of both twentieth-century humanitarianism and its twenty-first century 'post-humanitarian' mutations. Chouliaraki's concern is with the political and ethical problem of solidarity. While her discussion superficially resembles that of other contributors, her close attention to forms of mediation and their consonant affects, especially the differences between texts that use pity and those that depend upon irony to elicit humanitarian engagement, offers genuine insight into some ubiquitous features of contemporary culture, including celebrity humanitarianism and 'solidarity as self-fulfilment'. (88)

Whereas Chouliaraki productively works the ground between the empirical and the normative, Gunew's contribution is framed around the concept of vernacular cosmopolitanism. As most local readers will know, Gunew is a literary scholar who has contributed to critical debates on multiculturalism in Australia as well as Canada. Unsurprisingly, she here continues her primarily textual approach to the volume's theme but also shifts the focus from Europe to Australia via the discussion of literary works, including Antigone Kefala's Sydney Journals. In Kefala's hybrid text Gunew finds not only a 'mediating intellectual presence' with much to offer through its 'allegories of cosmopolitanism' (137) but also an 'Europeanness that is idiosyncratically conceived by all those who are linked to its varied histories'. (145) This version of a 'worlded' Europe is more attuned to the politics of location than that promoted by other scholars in this volume. Gunew's self-consciously minoritising (as opposed to elitist) 'estrangement as pedagogy' (145) is played out not through normative affirmation but through methods of reading and writing. Against the backdrop of the collection as a whole, Gunew's chapter feels strangely 
unfinished in a way that parallels the cultural space of the cosmopolitanism that she invokes.

The problems raised by this volume are ongoing ones for cultural studies: they involve unity of knowledge and the translation into method through which it is negotiated. If cosmopolitanism is to be more than the name for moral and political norms on the one hand, or the material condition of the contemporary on the other, we need to know how to proceed in the space of their convergence. The best of the contributions included in this volume address these questions of the where and the how of the study of cosmopolitan culture as well as the what and the who of cosmopolitical theory.

Adam Gall is an independent scholar based in Sydney. His current research explores the relationships between narrative, attachment and the ethico-political. <saukare@gmail.com>

${ }^{4}$ Ziauddin Sardar and Borin Van Loon, Introducing Cultural Studies, Icon Books, London, 1997, p. 9.
}

\section{-Bibliography}

Brook, S., 'Cultural Capital and Cultural Diversity', Journal of Australian Studies, vol. 32, no. 4, 2008. doi: http://dx.doi.org/10.1080/14443050802471418

Chatterjee, P., Lineages of Political Society, Columbia University Press, New York, 2011.

Chen, K-H., Asia As Method: Toward Deimperialization, Duke University Press, Durham, 2010. doi: http://dx.doi.org/10.1215/9780822391692

Hage, G., White Nation: Fantasies of White Supremacy in a Multicultural Society, Routledge, New York, 1998. 
Sardar, Z. and B. Van Loon, Introducing Cultural Studies, Icon Books, London, 1997.

Wise A. and S. Velayutham (eds), Everyday Multiculturalism, Palgrave Macmillan, New York, 2009. doi: http://dx.doi.org/10.1057/9780230244474 